\title{
Microstructural Modification of a Cast Iron by Magnetic Field Processing
}

\author{
E.A. Kenik*, G. Mackiewicz-Ludtka*, G.M. Ludtka*, J.B. Wilgen** and R.A. Kisner** \\ *Materials Science \& Technology Division and **Measurement Science \& Systems Engineering \\ Division, Oak Ridge National Laboratory, Oak Ridge, TN, 37831
}

Phase stability and phase transformations can be determined by magnetic field, as well as normal thermodynamic variables (e.g., temperature, pressure, number of elements present...), especially in ferromagnetic materials. The current study deals with the microstructural modification of a nodular cast iron during solidification under the influence of high magnetic fields (up to 18 tesla). An increase in hardness was observed with increasing field strength (from 278, 385 and $421 \mathrm{VHN}$ for the as-received, 4.5 and 9 tesla processed conditions).

The cast iron alloy was modified to substitute $\mathrm{W}$ for $\mathrm{Mo}$ (Fe-2.78C-0.135Cr-0.0743Cu-0.048Mg0.523Mn-0.0089Mo-0.0315Ni-4.98Si-0.174Ti-0.04V-1.322W (wt\%)). Magnetic field processing during solidification was performed in a custom induction furnace that fit in the bore of the 20 tesla magnet at the National High Magnetic Field Laboratory, Tallahassee, Florida. The solidification was performed under the influence of acoustical stimulation at a frequency of $11-12 \mathrm{kHz}$ that resulted from an electromagnetic acoustical transducer effect from the interaction of induction (heating) current with the static high magnetic field. Optical microscopy, analytical electron microscopy in a scanning electron microscope (SEM), an electron microprobe analyzer, and a transmission electron microscope (TEM), and X-ray diffraction were performed to characterize the microstructure and phases present as a function of magnetic field strength. TEM characterization was performed on focused ion beam (FIB) lift-out specimens in order to minimize the interference between the field of the objective lens and the ferromagnetic material, which made scanning transmission electron microscopy (STEM) X-ray microanalysis and specimen tilting relatively simple.

Backscattered electron (BSE) imaging in the SEM revealed the complex microstructure of the cast iron and the modification of the microstructure and phases present as a function of magnetic field (Fig. 1). The material cast under no magnetic field had a similar microstructure to the as-received cast iron, though on a slightly finer scale. The dark nodular phase (Fig. 1) is graphite, which is surrounded by a shell of columnar ferrite grains radiating from the nodules (Fig 2.a.). Pearlite, a lamellar mixture of ferrite and $\mathrm{Fe}_{3} \mathrm{C}$ cementite, is present on the outside of the ferrite shells (inset Fig. 2.a.). A fourth component of the microstructure consists of regions that image brighter than the matrix, indicating a higher average atomic number than ferrite (Fig. 2.b., inset).

As the magnetic field strength was increased, the graphite nodules changed from roughly equiaxed to agglomerates of smaller, more angular nodules. The density of the bright-imaging regions also increased with field strength. Both BSE imaging and X-ray microanalysis revealed that the brightimaging regions represented several different phases depending on the material condition. SEMbased EDS analysis indicated that all these phases were carbides enriched in W. Electron microprobe wavelength dispersive spectroscopy analysis provided a more quantitative evaluation of carbon levels and gave better separation of the $\mathrm{Si}-\mathrm{K}$ and $\mathrm{W}-\mathrm{M}$ lines (Table 1). The compositions quoted are for the 18-tesla-processed material, but the compositions for the as-received material were similar. Carbide 1 and Carbide 2 are the light-gray imaging and bright-imaging phases in the BSE images, respectively (inset Fig. 2.b.). This imaging behavior results from the presence of $\mathrm{W}$ in both phases and the higher $\mathrm{W} / \mathrm{Fe}$ ratio of Carbide2. The as-received material exhibited two morphologies of 
Carbide2, each with 45-50 at\% C. The first type was elongated, and the second type had an equiaxed, more angular morphology, and contained significant Ti (as high as 20 at \%) that replaced some of the $\mathrm{W}$ and $\mathrm{V}$ with respect to the Carbide 2 composition listed in Table 1. Image analysis of both optical and SEM BSE images was employed to quantitatively determine the volume fraction of several of the important phases present (Table 2). TEM and X-ray diffraction helped identify the bright-imaging phases, as well as differences in the two ferrites present. ${ }^{1}$

1. Research sponsored by the U.S. Department of Energy, Office of Energy Efficiency and Renewable Energy, Industrial Technologies Program, under contract DE-AC05-00OR22725 with UT-Battelle, LLC. Electron microscopy was performed at the SHaRE User Facility, sponsored at Oak Ridge National Laboratory by the Division of Scientific User Facilities, Office of Basic Energy Sciences, U.S. Department of Energy.

Table 1 Phase composition from electron microprobe analysis (at \%)

\begin{tabular}{|l|c|c|c|c|c|c|c|c|}
\hline & $\mathrm{C}$ & $\mathrm{Si}$ & $\mathrm{Ti}$ & $\mathrm{V}$ & $\mathrm{Cr}$ & $\mathrm{Mn}$ & $\mathrm{Fe}$ & $\mathrm{W}$ \\
\hline Ferrite & 0.6 & 10.1 & 0.0 & 0.0 & 0.1 & 0.4 & 88.8 & 0.1 \\
\hline Pearlite & 5.3 & 9.2 & 0.0 & 0.0 & 0.1 & 0.4 & 84.9 & 0.3 \\
\hline Carbide1 & 16.7 & 7.9 & 0.0 & 0.4 & 0.9 & 1.3 & 65.5 & 7.2 \\
\hline Carbide2 & 44.4 & 0.7 & 4.5 & 0.8 & 1.4 & 0.5 & 13.8 & 24.4 \\
\hline
\end{tabular}

Table 2 Volume fractions of phases present $(\%)$

\begin{tabular}{|c|c|c|c|}
\hline & Carbon nodules & Pearlite & Bright regions \\
\hline As-received & 9.7 & 10.9 & $0.7^{*}$ \\
\hline No field & 7.1 & 45 & $2.4^{* *}$ \\
\hline 18 tesla processing & 7.2 & 48 & $9.4^{* *}$ \\
\hline$*$ - Carbide2
\end{tabular}
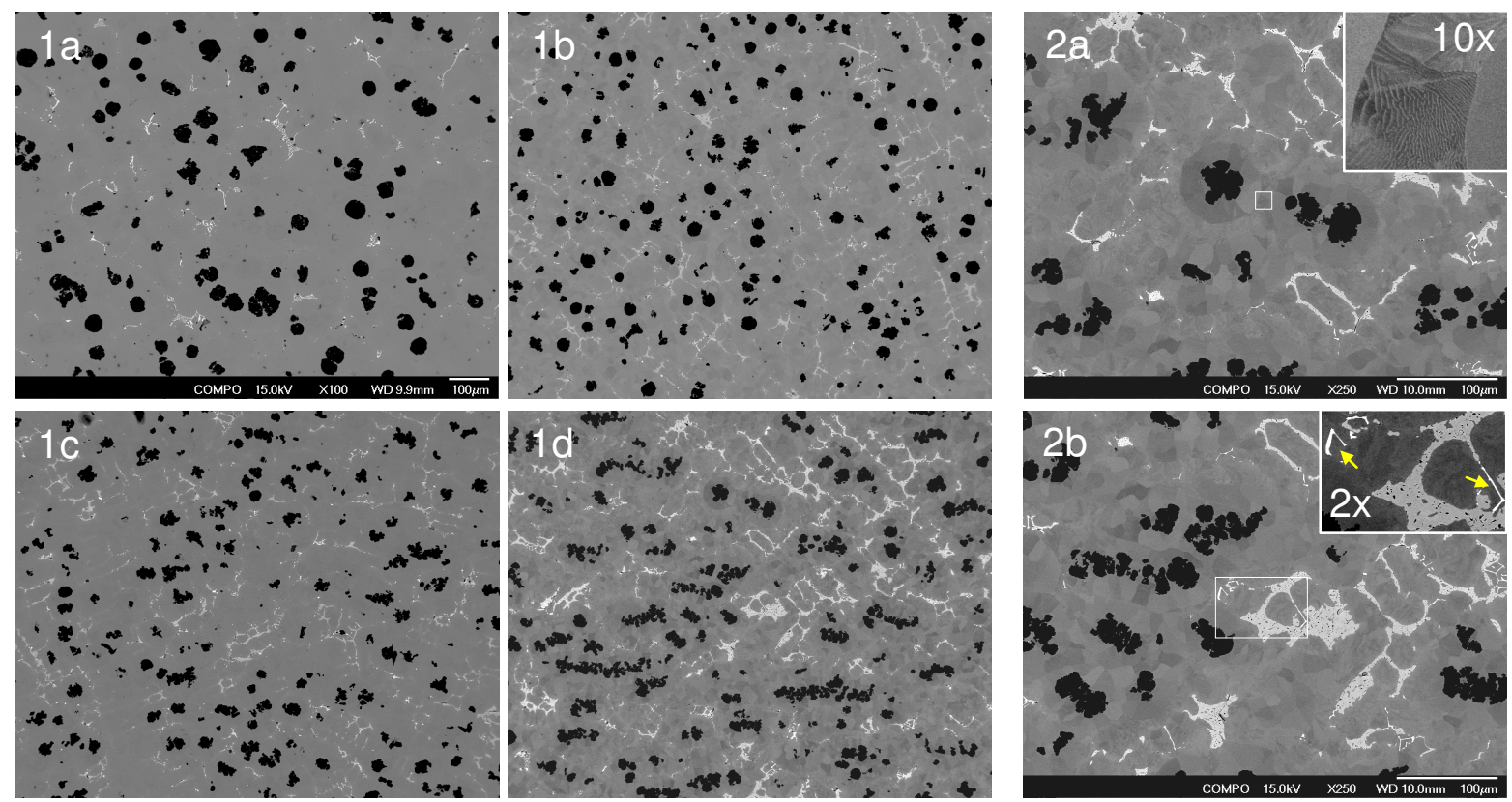

Fig. 1.a.-d. BSE images of cast iron as-received and processed under 0, 4.5 and 18 tesla fields, respectively. Note morphology change of the nodules and the increase of bright-imaging phases with increasing field level.

Fig. 2.a. Higher magnification BSE image of cast iron re-cast under 18 tesla field. Note ferrite shells surrounding graphite nodules and pearlite between ferrite shells (inset - small square enlarged).

Fig. 2.b. Higher magnification BSE image of cast iron re-cast under 18 tesla field. Note the spatial separation of the nodules from the two bright-imaging phases (inset - small rectangle enlarged). 